\title{
Participación y ciudadanía en el contexto actual
}

\author{
Participation and citizenship in the current context \\ Piero Viteri
}

Universidad de Santiago de Chile

\section{Introducción}

Discutir el tema de la participación está de moda. En los ayuntamientos, los parlamentos, las asociaciones civiles, en los organismos internacionales, los partidos políticos y las asociaciones religiosas. ¿Por qué hablar de participación?, ¿En qué consiste?, ¿Cómo puede llevarse a la práctica en el contexto local actual?, ¿Con qué experiencias se cuenta?. Estudiar el fondo de la participación involucra reflexionar sobre lo que constituye el espacio de lo público, no solamente en sus aspectos culturales o cognitivos, sino también, en sus expresiones estratégicas o instrumentales, todos los cuales tienen afinidad con la forma de gestionar las políticas públicas, y por lo tanto, las de participación de la ciudadanía. Concebimos por espacio de lo público un concepto analítico, que alude al interés colectivo que fundamenta cualquier definición de sociedad. Nos ayudará para explorar relaciones sociales, competencias institucionales y su división en diversos elementos, históricamente asumidos en forma diferencial por diversos aparatos estatales, civiles o religiosos. Me interesa entender el concepto de lo público en el sentido de aquello que expresa algo opuesto al interés privado, que apunta al bien colectivo, aún cuando sea para argumentar acciones en contra de otros colectivos. Explorar la evolución de este espacio nos lleva a reflexionar sobre la formación del poder político como un ámbito autónomo de la sociedad, y a la factura de una solución de continuidad entre gobernantes y gobernados, que hace que hoy sea necesario hablar de participación.

\section{La crisis de la política represen- tativa}

A pesar de que el sufragio universal y el régimen de partidos se han institucionalizado como los símbolos de identidad más evidentes de las democracias modernas, existe un fenómeno que atenta contra la legitimidad del sistema mismo, que es el abstencionismo electoral. Para algunos el absten-

*Dirección de correspondencia [Correspondence address]: Piero Viteri, Universidad de Santiago de Chile E-mail: piero.viteri@usach.cl cionismo es una actitud en buena medida motivada por numerosos escándalos de corrupción e ineficiencia de los políticos. A la vez, la presencia de movimientos "anti-sistema", que van desde neofascistas pasando por movimientos anarquistas y contestatarios hasta los independentistas; todos estos sectores de la sociedad pueden ser interpretados como signos de desaliento en relación a la política tradicional, basada en la representatividad.

Los niveles de abstención actuales expresan una brecha entre gobierno y ciudadanía siendo más elocuente su expresión en el nivel local, donde las posibilidades de incidir en la gestión de lo público serían en teoría más factibles y operativas, donde el conocimiento local de los pobladores de una ciudad, de un barrio, podría ser más favorable incorporado a las políticas. La brecha es tan manifiesta, que resulta común que entre los ciudadanos e incluso entre sus líderes de opinión se equipare Estado con política y gestión pública con gestión de lo público. La demarcación de una clase política frente a la sociedad civil que se reproduce a nivel local, obliga a replantear el modelo dominante de democracia representativa, cuestionando sus componentes de distancia y profesionalización (Pindado Sánchez, 2000)

Para algunos, la brecha entre política y ciudadanía es producto del fenómeno de la profesionalización de la política, situación que parece inevitable y acaso necesario para la complejidad derivada de las características de las sociedades modernas y de la necesidad de introducir modelos eficientes de gestión. De la misma forma, en esta racionalidad burocrática, se documentan además tendencias a perpetuarse en el poder de estos corporativos, gracias a conductas nepotistas y clientelares, con escasa movilidad y rotación de funcionarios.

La dinámica electoral se mantiene atinadamente, sin embargo el debate político se ha trasladado a las instituciones. Los partidos políticos monopolizan el ámbito de decisión de las intervenciones municipales de tal forma que, la gestión de la cosa pública queda como algo que solo compromete a los políticos, los cuales al votar de forma corporativa comprometen la defensa de intereses partidistas. El tamaño y la complejidad de las grandes organizaciones técnicas que requiere actualmente la administración pública, se presenta como una de las razones más importantes para justificar la ausencia 
de los ciudadanos de los mecanismos de gestión, debiendo estos limitarse a gozar de derechos y cumplir obligaciones según dictan las leyes elaboradas por los canales políticos (Bobbio, 2003).

El llamado "desencanto con la política" por parte de los ciudadanos tiene mucho que ver también con la difusión, generalizada por los medios de comunicación, de numerosas denuncias de corrupción tanto al interior de los partidos como de las instancias de gobierno. Se fundamenta también en la constatación de que la política ha devenido en un espectáculo, de continua exacerbación, como sucede en tiempos electorales, agravado por las características del actual marketing político, en el cual la distinción entre candidatos y programas de los distintos partidos políticos se diluye en pos de mantener su posición de poder.

Otro enfoque sobre el tema de la crisis política actual se relaciona con algo que se puede llamar como el secuestro de la ciudadanía. Donde el ciudadano, tiene la impresión de que la mayoría de las decisiones importantes son pactadas fuera del ámbito público, ya sea porque corresponden a instancias negociadas entre los diversos niveles de gobierno y los partidos, o porque son diseñadas en ámbitos lejanos, como sucede con las diversas consecuencias derivadas de la globalización económica.

Sin embargo, la apatía política no abarca a todos los ciudadanos, pues hay quienes organizados o no, se manifiestan por cauces distintos a las vías electorales. De esta forma, los canales formales de participación de los ciudadanos se ven cada vez más desplazados por otras expresiones alternativas de representación. Las reivindicaciones toman frecuentemente el sesgo de los desencuentros entre ayuntamientos y la ciudadanía, manifiestándose en la forma de cartas a los diarios, firmas de peticiones, graffitis, etc. Puede afirmarse incluso que el contraste principal que existe actualmente no es entre un grupo reducido y politizado y una mayoría pasiva e inhibida, sino entre un grupo con politización integral y una mayoría que posee una politización selectiva Para algunos autores constituyen la expresión de un ámbito de diferenciación social, el de "lo subpolítico", en el cual las demandas se canalizan en formatos distintos a los burocráticos y políticos habituales (Beck, 1997).

\section{Discusiones sobre el concepto de participación}

En una sociedad globalizada, la participación genera un doble discurso. Por un lado, se aboga por ella desde el Estado y la sociedad civil; por otro, hay una fuerte tendencia a acallar los conflictos sociales que surgen de la pugna de intereses contrapuestos, no asumiéndolos como parte del escenario de una verdadera democracia.

Diversos autores coinciden en el planteamiento sobre la amplitud y ambigüedad del concepto de participación. Como concepto sujeto a un sinnúmero de interpretaciones, hace imposible el tratamiento del tema en una sola perspectiva; la participación aparece por lo tanto, con un contenido diverso de acuerdo al contexto discursivo en el cual se instale. A ello se suma la dificultad de precisar con exactitud las diferentes modalidades de participación: la política, la social, la ciudadana.

Hay acuerdo en que el quebrantamiento de la vida comunitaria y la pérdida de los valores que le otorgan sentido a la acción colectiva han generado un debilitamiento de la participación. Se entiende a esta como un eje central del desarrollo del país, reconociendo las enormes potencialidades que este proceso juega en la profundización de la democracia y en el mejoramiento de la sociedad en su conjunto. Se asiste a una revalorización de la participación social y política y se comprende que no habrá equidad sin participación.

Hasta ahora, se ha pensado la participación como un complemento importante de la democracia. Tal es así que se habla de pasar de un tipo de política asistencial a otra que ponga en movimiento la capacidad de la misma gente para salir adelante, esto es involucramiento de los propios interesados en la solución de los problemas que los aqueja.

Otro planteamiento hace referencia al hecho de que el mejoramiento real de las condiciones de vida de los sectores más postergados pasa, necesariamente, por ampliar los espacios y canales de participación de las personas, para que éstas puedan intervenir en todos los ámbitos de la vida social.

La participación en su dimensión ciudadana significa la inclusión de la ciudadanía en los procesos decisorios incorporando intereses particulares (no individuales), pero para que esto sea posible se deben abrir espacios de participación con reglas claras las cuales deben regir las relaciones de los actores involucrados en estos procesos. Es decir, la participación genera compromisos institucionales y exige crear un clima de trabajo comunitario en el que exista el convencimiento de que la deliberación pública, la interacción social y el respeto por el pluralismo son valores y prácticas positivos y esenciales de la democracia (Ziccardi, 2004: 246-247).

El componente instrumental también se ha dado en las instancias de participación impulsadas por 
las propias personas. Hoy en día se plantea, que lo que se ha debilitado son las organizaciones sociales permanentes. Frente a determinadas situaciones la gente se organiza, pero al resolver el problema, la organización se diluye. Las experiencias de participaciones meramente instrumentales, no sustantivas, inevitablemente van soslayando las capacidades de las personas de constituirse en sujetos activos y constructores de una sociedad distinta y mejor.

El componente cultural también ha tenido su peso en este debilitamiento. Hemos pasado de una cultura con gran valoración de lo colectivo a un sobredimensionamiento de lo individual, hecho que hace decaer fuertemente la organización, como resultado del deterioro del tejido social. En tal sentido, creo que la amplitud del proceso de participación pasa necesariamente por una preocupación por el capital sociocultural y político que permita efectivamente la incorporación de todos los ciudadanos en la labor de desarrollo del país.

\section{Enfoques y definiciones}

Una primera perspectiva sobre la participación plantea la calidad de la democracia no está determinada por la participación ciudadana sino que la mayoría de los que efectivamente participan, a partir de sus intereses individuales y egoístas, determinan quién decide por todos (Salazar, 2004). En esta perspectiva conceptual, la participación define dos posibilidades en relación con el poder. Primero, la participación como proceso en el marco territorial de instancias locales, prioriza la acción organizada como modalidad de influir en la toma de decisiones, por tanto referida al poder local. La otra modalidad se refiere a la participación con un carácter macrosocial, se especifica cuando la comunidad participa con su voto en las elecciones para decidir sobre proyectos generales.

El segundo enfoque conceptual de Salazar (2004), se refiere a las teorías deliberativas inspiradas principalmente en el pensamiento de Habermas. Este enfoque enfatiza la participación como una conducta que permite fortalecer la personalidad y la capacidad de las personas para enfrentar desafíos. La participación expresa en sí misma un valor que funda las posibilidades de autodesarrollo humano, se destaca tanto su efecto pedagógico, como su función educativa, donde lo central está dado por la idea de actuar, es decir, la acción entendida como eje en la producción y reproducción de la cultura.

Una tercera mirada, se refiere a las teorías constitucional/sustantivas que sostiene que el ideal democrático y el ideal constitucional se encuentran estrechamente relacionados, al grado que los derechos fundamentales de libertad, políticos y sociales, constituyen una dimensión sustantiva de la democracia, cuyo valor radica en su defensa y sus garantías, pero que devalúa la importancia de la participación ciudadana en la adopción de políticas públicas (Salazar, 2004).

Se destaca en la conceptualización hecha, el alcance que el proceso de participación revierte, en tanto se define como sujeto a toda la sociedad, es decir grupos sociales, personas, familias regiones y comunas. Asimismo, objeto y objetivos de la participación apuntan en dos sentidos: la satisfacción de necesidades sociales a toda la población especialmente los más marginados; la expansión de capacidades de las personas. Ello abre la posibilidad de desarrollo más integral, que se exprese en una mejor calidad de vida.

La participación se plantea en una doble dimensionalidad: la individual y la colectiva, se vincula a un proyecto y metas de base social, con una determinada concepción de bien común, ligada a la promoción de hombres y mujeres y al respeto y confianza en el otro social. La perspectiva ética de la participación que rescata la solidaridad como elemento central, nos permite entenderla como un valor social centrado en la persona humana; nos constituimos como tal, en la medida que actuamos con otros y nos hacemos sujetos en la toma de decisiones, es decir, lo que para algunos significa constituirse en protagonistas de la historia con capacidad para autodeterminarse.

\section{Política local en un mundo glo- bal}

Emprender el tema de la participación en el contexto actual obliga a describir dos fenómenos que aunque opuestos en escala, aparecen profundamente unidos: la incidencia de la esfera local en el ámbito político y las tendencias que impone la globalización a las sociedades actuales. Hay que tener presente, en el primer caso, que en el nivel local la cercanía entre los actores sociales y la práctica política como experiencia intersubjetiva son factores que en el caso de las urbes europeas han estado presentes desde la ciudad antigua.

No está demás señalar que los municipios disponen de dos significativas ventajas en relación a otras instituciones de carácter público. En primer lugar, gozan de mayor capacidad de representación y de legitimidad en relación a sus representantes: son agentes institucionales de integración social y 
cultural de sus comunidades. En segundo, gozan de mucha más flexibilidad, adaptabilidad y capacidad de maniobra ante una realidad colmada de oleadas entrelazadas, demandas y ofertas variables y sistemas tecnológicos descentralizados e interactivos (Borja y Castells, 1997).

Los sucesos de la política en el nivel local, a diferencia de la política estatal o autonómica, no se contemplan a distancia, sino que es vivida como una experiencia intersubjetiva dentro de lo que aquí nominaremos un mundo local moral, que no tiene una delimitación geográfica ni administrativa, y que responde a la manera como cada día se construye a nivel ciudadano la experiencia política en el ambiente próximo, cuya percepción por parte de los actores constituye su mundo local. Si reflexionamos estos factores, la abstención electoral a nivel local enunciaría una discordia mucho más profunda que a escala estatal o autonómica, entre la representación electoral y la vivencia de la experiencia política por parte de la ciudadanía, precisamente porque a escala local se vive y se incorpora cotidianamente la experiencia de la política sin necesidad de mediación. Estos elementos funcionan con otros en la escala de la política distante, como la representada en las Cortes Generales o en el Parlamento catalán, pero son menos aceptables en el nivel local, especialmente si hablamos de pueblos o ciudades medianas donde los alcaldes y regidores suelen ser vecinos, formando parte del entorno cotidiano que ofrecen las relaciones cara a cara. El factor de proximidad, introduce elementos diferenciadores, por lo cual la abstención y la no participación en el nivel local manifiesta hechos más graves que en los niveles más extensos.

Tienden, además, a modificar en forma importante la vida local a partir del efecto emergente de lo "glocal", una revaloración de lo que está más cercano, lo que es nítidamente local y vivido por lo tanto directamente, pero que maneja en función de acontecimientos que tienen lugar a muchos kilómetros de distancia (Giddens, 1993). La mundialización se refiere a la globalización de la economía, al papel medular de las finanzas, la emergencia de la sociedad de la información, el papel de los medios de comunicación globales y la constitución del mercado mundial. Se dirige a una intensificación de las relaciones sociales en todo el mundo por las que se conectan lugares lejanos, de tal manera que los eventos locales están conformados por situaciones a escala mundial, pero también, lo que sucede en el medio local puede repercutir potencialmente en espacios mas amplios, un aspecto que por estar generalizado pasa comúnmente desapercibido. Ofrece un potencial que las actuales tecnologías virtuales, como internet, tienden a activar, anuncian la evolución hacia formas de organización e integración social cada vez mas complejas y desterritorializadas (Castells, 2005).

Los resultados de la globalización y sus interpretaciones "glocales" tienden a minar el dominio de lo político para llevar a espacios desconocidos, como el capital financiero y el avance tecnológico a nivel internacional, el eje de decisiones cuyas secuelas pueden ser involuntarias e inesperadas, realizadas en nombre del interés privado o de grupos corporativos determinados, aun cuando puedan invocar o encubrirse de lo contrario. El poder de las trasnacionales ha alcanzado tal magnitud que amenaza con convertir a los gobiernos nacionales en marionetas de sus intereses, aun cuando en el desconcierto resultante lo que predomina como diagnóstico es que la rapidez y complejidad de los procesos económicos y financieros actuales causan efectos no esperados, el concurso agudo de la incertidumbre y un ambiente caracterizado por el riesgo.

El desencanto con la actividad política que se ha intensificado desde fines del siglo XX, deriva en gran parte, de la retórica de la globalización, según la cual la acción política está esclavizada al funcionamiento de los mercados financieros, algo que el plano ideológico se traduce en el predominio de los medios de comunicación que no son necesariamente locales. Asimismo, los ciudadanos están más familiarizados con noticias del nivel nacional o regional a costa de saber lo que acontece en su contexto más inmediato. La autonomía de los nuevos medios de comunicación globales, que implican enormes movilizaciones de capital y por tanto su subordinación a los intereses de los grandes grupos financieros; los medios de comunicación, con sus oportunos objetivos y fines han envuelto, entre otras cosas, la adecuación del discurso político a la lógica mediática, poniendo la imagen y el marketing por encima del debate y las propuestas políticas. La opinión noticiada suplanta el ejercicio de la opinión pública, la prensa y otros medios de comunicación dejan de ser zonas de discusión y acción democratizadora para convertirse en vehículos publicitarios de gobierno o testimonios amarillistas manipulados por la captura del interés fácil del ciudadano espectador (Vallespín, 2000). La contradicción es que la libertad de expresión queda coartada, en un régimen de derechos constitucionales, porque los medios sólo favorecen aquellos discursos compatibles con los intereses que representan o para ganarse la protección financiera de las autoridades de gobierno, en un contexto en el cual sin esta protección el acceso a los recursos puede verse en peligro.

El acento en Europa de la participación social había girado en entorno a las políticas de ayuda recíproca como respuesta al liberalismo radical y al capitalismo cruel del siglo XIX. Una vez venci- 
das en buena parte estas catástrofes y asegurada la paz social, las sociedades europeas se enfrentan con dos problemas que antes estaban olvidados a un segundo plano y que hoy, como consecuencia de procesos internacionales vuelven a tener particular validez. Primero, la diversidad cultural emanada de los procesos migratorios; y en segundo término, los nuevos procesos de exclusión, marginación y desafiliación que caracterizan a una parte de estos y otros grupos sociales que pueden ser tanto legales como ilegales. En un contexto donde el modelo clásico de integración social ha entrado en conflicto como principal resultado de las presiones que recibe el Estado en la nueva fase de globalización capitalista. En medio de este cuadro de crisis e inseguridad y de discursos contradictorios, ha brotado un discurso de rutas intermedias, que es la que caracteriza hoy los alegatos políticos centristas tanto de derecha como de izquierda, cuyo objetivo parece ser articular la conversión de la política en instrumento de transmisión de los capitales financieros con el alejamiento de sus funciones de arbitraje. Todo esto puede, de alguna manera, explicar para el caso europeo la animosidad de buena parte de la ciudadanía hacia la participación política en los términos en que esta se ha concebido tradicionalmente en el viejo continente, es decir, la participación electoral, la militancia política y la afiliación a sindicatos. A pesar de esta realidad, cabe señalar que también en Europa el sector de las agrupaciones ciudadanas ha conocido un fabuloso auge en las últimas décadas, que choca con el alejamiento de la población respecto a los núcleos de decisión. Algo que en la actualidad puede admitirse como un asunto agravado con los procedimientos de la Unión Europea y los efectos de la globalización económica, los cuales tienden a socavar competencias de los gobiernos nacionales y locales e influir activamente en sus entornos geográficos y sociales.

\section{Referencias}

Beck, U. (1997). Modernización reflexiva: política, tradición y estética en el orden social moderno. Alianza, Madrid.

Bobbio, N. (2003). El futuro de la democracia. Fondo de Cultura Económica, México D.F.

Borja, J. y Castells, M. (1997). Local y global: la gestión de las ciudades en la era de la información. Taurus, Madrid.

Castells, M. (2005). La era de la información: economía, sociedad y cultura. Siglo XXI, México. D.F.

Giddens, A. (1993). Consecuencias de la modernidad. Alianza, Madrid.

Pindado Sánchez, F. (2000). La Participación Ciudadana en la Vida de las Ciudades. Ediciones del Serbal, Barcelona.

Salazar, P. (2004). '?qué participación para cuál democracia? En Ziccardi, A., editor, Participación ciudadana y políticas sociales en el ámbito local. IIS-UNAM, México D.F.

Vallespín, F. (2000). El futuro de la política. Taurus, Madrid.

Ziccardi, A., editor (2004). Participación ciudadana y políticas sociales en el ámbito local. IISUNAM, México D.F. 